(Survey Pada Tamu yang Pernah Menginap di Resort)

\title{
PENGARUH SERVICESCAPE TERHADAP CUSTOMER DELIGHT PADA TAMU RESORT (Survey Pada Tamu yang Pernah Menginap di Resort)
}

\author{
Dewi Mei Liyani ${ }^{(1)}$, A.H.G. Kusumah ${ }^{(2)}$, Rosita $^{(3)}$ \\ (1)(2)(3) Program Studi Manajemen Resort \& Leisure \\ Universitas Pendidikan Indonesia \\ dewimeiliyani@gmail.com
}

\begin{abstract}
ABSTRAK
Servicescape penting dalam industri pariwisata karena pengalaman berwisata bersifat abstrak sehingga wisatawan membutuhkan tanda-tanda fisik yang bisa menjadi bukti bahwa mereka akan mendapatkan sesuatu yang menyenangkan. Penelitian ini bertujuan untuk mengetahui bagaimana pengaruh Servicescape (X) terhadap customer delight (Y) pada tamu resort. Penelitian ini menggunakan pendekatan kuantitatif, dengan cara penelitian menggunakan kuesioner. Populasi dalam penelitian ini yaitu pengunjung yang pernah menginap di resort. Sedangkan sampel yang diambil dengan menggunakan rumus slovin sebanyak 100 responden. Teknik analisis data yang digunakan adalah teknik regresi linear berganda. Hasil penelitian ini menunjukan bahwa Servicescape berpengaruh sebesar 73,4\% terhadap customer delight, dan sisanya sebesar $(0,5157) 2=0,2659 \times 100 \%=26,59 \%$ dipengaruhi oleh faktor lain yang tidak termasuk ke dalam penelitian ini. Kondisi ini mengindikasikan Servicescape dapat mempengaruhi customer delight dan faktor lain di luar dari Servicescape tidak memiliki pengaruh besar. Hal ini menunjukan bahwa Servicescape berpengaruh positif terhadap customer delight dan Servicescape yang ada masih harus dioptimalkan dan dipelihara.
\end{abstract}

Kata kunci: Servicescape, customer delight, tamu resor.

\section{THE EFFECT OF SERVICESCAPE ON DELIGHT CUSTOMER AT THE RESORT GUEST (Suervey for guests who have stayed at a resort)}

\section{ABSTRACT}

Servicescape is important in the tourism industry because the travel experience is abstract so tourists need physical signs that can be proof that they will get something fun. This study aims to find out how the influence Servicescape $(X)$ to customer delight $(Y)$ on the resort guests. This research uses quantitative approach, by means of research using questionnaire. The population in this study is the visitors who had stayed at the resort. While the samples taken using slovin formula as much as 100 respondents. Data analysis technique used is multiple linear regression technique. The result of this research shows that Servicescape has 73,4\% influence to customer delight, and the rest equal to $(0,5157)^{2}=0,2659 \times 100 \%=26,59 \%$ influenced by other factors not included in this research. This condition indicates that Servicescape can affect customer delight and other factors outside of Servicescape have no greater effect. This shows that Servicescape has a positive effect on customer delight and existing Servicescape must still be optimized and maintained.

Keywords: planning, recreational activity, learning of traffic knowladge. 


\section{PENDAHULUAN}

Servicescape yang secara sengaja dibuat memiliki peran penting dalam mempengaruhi perilaku konsumen pada lingkungan jasa. Servicescape mempunyai hubungan yang erat dan mempengaruhi kepuasan pelanggan. Semakin baik Servicescape yang diberikan maka semakin tinggi pula tingkat delight. Kualitas yang diterima dari Servicescape akan menyebabkan kepuasan dan pembelian berulang pada penyediaan jasa. Jika pelanggan menyukai Servicescape yang diberikan pihak penyedia jasa layanan maka ia akan merasa puas. Hal ini disebabkan perasaan menyukai identik dengan perasaan senang dan pelanggan yang merasa senang berarti besar peluangnya ia merasa puas dan menjadi loyal.

Servicescape penting dalam industri pariwisata karena pengalaman berwisata bersifat abstrak sehingga wisatawan membutuhkan tanda - tanda fisik yang bisa menjadi bukti bahwa mereka akan mendapatkan sesuatu yang menyenangkan. Penelitian ini bertujuan untuk mengetahui pengaruh Servicescape terhadap customer delight. Pengumpulan data pada penelitian ini rencananya akan dilakukan pada wisatawan yang pernah berkunjung atau menginap di sebuah resort. Servicescape termasuk fasilitas eksterior dan interior. Servicescape dibuat oleh destinasi wisata agar para pengunjung betah dan akan kembali lagi untuk mengunjungi dan menyaksikan pertunjukan atau produk yang dijual di destinasi wisata tersebut.

Dalam konsep pemasaran jasa, tujuan perusahaan tentu ingin memberi kepuasan kepada pelanggan dan tidak ingin membuat pelanggan kecewa. Setidaknya beberapa perusahaan masih berada pada tingkatan tersebut, tetapi ada perusahaan lain yang ingin membuat pelanggan tidak hanya puas tapi lebih daripada itu, perusahaan ingin melebihi harapan pelanggan yang menggunakan produk dan jasa yang diproduksi. Customer delight berhubungan dengan kepuasan tetapi memiliki perbedaan, perbedaan itu karena customer delight berada di tingkatan yang berbeda. Tingkatan kepuasan pada delight curve dapat menunjukan pelanggan berada di zone of pain, zone of mere satisfaction dan zone of delight. Menurut Keiningham, et.al dalam Hariri (2009:71) Area ketiga yaitu zone of delight adalah zona pencapaian yang terbaik. Perusahaan tidak hanya membuat pelanggan merasa puas tapi juga memberikan value yang bernilai positif dan tidak disangka sebelumnya, beberapa faktor tersebut membuat pelanggan merasa delight, area ini terget pencapaian dalam industri pariwisata terutama jasa akomodasi.

Resort-resort di Indonesia tentu menerapkan program Servicescape, Kusumah (2017). Sebagai contoh Nirwana Gardens Resort Bintan, Padma Resort dan Hotel, Nihiwatu Beach Resort, Trans Resort Bali dan masih banyak resort lainnya yang menerapkan program Servicescape. Maka sudah tidak heran lagi jika banyak wisatawan yang berkunjung kesana lebih dari satu kali.Sebagai salah satu resort favorit pilihan wisatawan, maka pelayanan yang diberikan juga maksimal. Resort tersebut tentunya sudah tidak diragukan lagi kualitasnya.

Berdasarkan data dari hasil penyebaran kuesioner kepada 100 responden, terdapat beberapa resort terkenal di Indonesia yang menjadi tujuan responden berwisata. Berikut diagram berdasarkan lokasi tempat responden menginap :

\section{Presentase Resort Tempat Menginap}

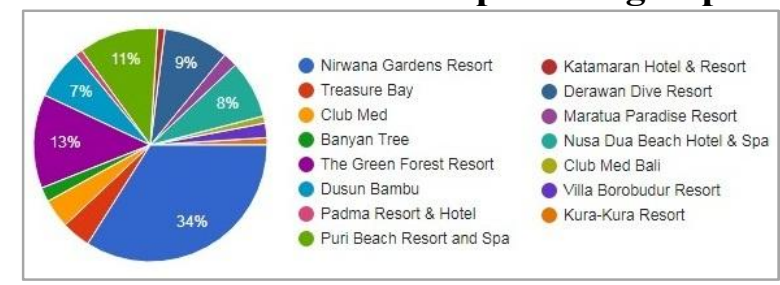

\section{Gambar 1. Diagram Presentase Resort} Tempat Menginap

Terlihat pada gambar 1 jika terdapat 15 resort yang menjadi lokasi menginap responden saat berwisata. Diantaranya Nirwana Gardens Resort Bintan, Treasure bay Bintan, Club Med Bintan, Banyan Tree Resort Bintan, The Green Forest Resort 
Bandung, Dusun Bambu Bandung, Padma Resort \& Hotel Bandung, Puri Air Beach Resort and Spa Lombok, Katamaran Hotel \& Resort Lombok, Derawan Dive Resort Kalimantan, Maratua Paradise Resort Kalimantan, Nusa Dua Beach \& Spa Bali, Club Med Bali, Villa Borobudur Resort Jawa Tengah, dan Kura-Kura Resort Karimunjawa. Dari 15 resort tersebut beberapa resort tidak hanya terkenal di Indonesia saja bahkan sampai mancanegara. Sebagai salah satu resort favorit pilihan wisatawan, maka pelayanan yang diberikan juga harus maksimal, tentunya resort-resort tersebut sudah tidak diragukan lagi kualitasnya.

Manajemen sebuah resort tentu ingin memberikan rasa delight kepada tamu yang menginap karena hal tersebut merupakan target yang ingin dicapai oleh manajemen sebuah resort. Hal ini cukup beralasan karena tamu telah menghabiskan biaya yang tidak sedikit agar dapat merasakan kemewahan dari fasilitas dan pelayanan sebuah resort. Akan tetapi untuk mencapai target tersebut cukup sulit. Kendala untuk memenuhi pelayanan dan fasilitas fisik antara lain tamu yang datang dengan harapan tinggi dan ingin mendapatkan pelayanan yang cepat dengan kualitas terbaik terkadang menghadapi kendala. Permintaan tamu seringkali muncul pada waktu yang hampir bersamaan seperti saat reservasi, checkin dan check out sehingga rasa delight yang menjadi target tidak dapat tercapai. Tamu belum sempat mencoba seluruh fasilitas hotel karena tidak sedikit dari tamu melakukan kegiatan bisnis sehingga berdampak pada kurangnya waktu untuk menikmati fasilitas hotel secara maksimal. Tamu juga belum mengetahui seberapa tinggi kualitas, keunikan, dan seberapa eksklusif fasilitas yang ada di resort tempat ia menginap.

Untuk mencapai target tersebut diperlukan strategi agar lingkungan fisik dan kinerja karyawan dapat memberikan rasa delight kepada tamu, strategi yang mencakup keseluruhan aspek tersebut adalah strategi
Servicescape. Dimana strategi utama yang diterapkan agar fasilitas fisik dan pelayanan dapat melebihi ekspektasi tamu. Seperti yang sudah disebutkan sebelumnya bahwa dalam Servicescape terdapat lingkungan fisik dan kualitas pelayanan karyawan itu sendiri. Servicescape memiliki dimensi yang terbentuk dari penelitian-penelitian sebelumnya. Diantaranya adalah ambient factors (faktor lingkungan) seperti suhu, musik, pencahayaan, dan aroma telah diidentifikasi sebagai elemen ambient yang relevan di lingkungan. Kemudian design factors (faktor desain) elemen lingkungan yang lebih bersifat visual daripada faktor lingkungan. Elemen semacam itu bisa fungsional atau estetis yang mencakup unsur-unsur seperti tata letak, kenyamanan, dan privasi, kemudian mencakup hal-hal seperti arsitektur, warna, bahan dan gaya. Selanjutnya social factors (faktor sosial) yang terkait dengan orang-orang yang hadir dalam lingkungan selama perjumpaan layanan. Hal ini diakui bahwa kehadiran fisik orang lain (karyawan, pelanggan) adalah elemen lingkungan yang penting.

Salah satu manfaat dari Servicescape adalah membuat wisatawan merasa senang dan puas dengan fasilitas yang lengkap. Perusahaan bahkan harus menciptakan sesuatu hal yang menghubungkan nilai dari mempertahankan pengunjung yang menguntungkan perusahaan. Keputusan pengunjung merupakan suatu hal yang penting dalam jangka panjang perusahaan. Ketika perusahaan mengembangkan fasilitas fisik yang lebih baik, maka akan mengarahkan pada loyalitas pengunjung yang lebih baik.

Sebuah resort menerapkan program Servicescape agar mampu melebihi pemenuhan harapan tamu sehingga perasaan delight dapat dipertahankan atau bahkan ditingkatkan.

\section{LANDASAN TEORI \\ Definisi Servicescape}

Para ahli saat ini memiliki berbagai pendapat tentang Servicescape, ada yang berpendapat 
Servicescape hanyalah elemen fisik, ada yang berpendapat Servicescape sangat luas karena adanya unsur social Servicescape yang sudah tentu melibatkan unsur manusia di dalamnya. Servicescape dapat ditemukan diberbagai bidang sehingga terkadang perbedaan itu dapat mempengaruhi pendapat akan Servicescape.

Proses penyampaian bukti fisik (physical evidence) yaitu melalui Servicescape. Menurut Hightower (2009:381) Servicescape didefinisikan sebagai "the Servicescape define here in as everything that is physically present around the consumer during their service encounter transcation" yang artinya segala sesuatu yang secara fisik hadir di sekitar konsumen selama pertemuan transakasi layanan jasa.

Selain itu menurut Zeithmal dan Bitner (2009:313) Servicescape didefinisikan sebagai:"Physical evidence as the service environment in which the service is delivered and in which the firm and customer interact, and any tangible commodities that facilitate performance or communication of the service" yang berartikan servicesape adalah lingkungan dimana jasa disampaikan dan dimana perusahan dan konsumennya berinteraksi, serta setiap komponen berwujud yang memfasilitasi penampilan atau komunikasi dari jasa.

\section{Dimensi Servicescape}

Servicescape memiliki dimensi yang terbentuk dari penelitian-penelitian sebelumnya. Dalam penelitian ini, peneliti menggunakan dimensi Servicescape menurut Hightower dan Shariat (2009, hlm. 379) di antaranya :

\section{Ambient Factor}

Faktor lingkungan didefinisikan sebagai kondisi non-visual dan latar belakang di lingkungan layanan seperti suhu, musik, pencahayaan, dan aroma telah diidentifikasi sebagai elemen ambien yang relevan di lingkungan tertentu. Namun faktor lingkungan mungkin dalam keadaan tertentu berlawanan dengan intuisi. Secara khusus berarti bahwa elemen ambient tertentu dapat diharapkan masuk sebagai bagian dari item penilaian akhir, padahal kenyataannya konsumen tidak mempertimbangkan unsur ambient yang diharapkan sebagai bagian dari lingkungan fisik penyedia layanan tersebut. Contoh khas dari ini mungkin musik. Penggunaan musik latar belakang mungkin tidak sepenting konsumen dibeberapa industri. Oleh karena itu, musik tidak muncul dalam intrumen penilaian layanan sebagai item ambient meskipun beberapa periset berpikir musik itu adalah barang ambient universal.

\section{Design Factor (Faktor desain)}

Faktor desain adalah elemen lingkungan yang lebih bersifat visual daripada faktor lingkungan. Elemen semacam itu bisa fungsional dan/atau estetis. Yang pertama dapat mencakup unsur-unsur seperti tata letak, kenyamanan, dan privasi, sementara yang kemudian mencakup hal-hal seperti arsitektur, warna, bahan, dan gaya.

\section{Social Factor (Faktor Sosial)}

Faktor sosial adalah rangsangan yang terkait dengan orang-orang yang hadir dalam lingkungan selama perjumpaan layanan. Hal ini diakui bahwa kehadiran fisik orang lain (karyawan, pelanggan) adalah elemen lingkungan yang penting.

\section{Customer Delight}

Kwong (2002:260) yang mendefinisikan dimensi customer delight yang didasari lima kebutuhan dasar manusia yaitu :

1. Justice

Konsumen menuntut kesepakatan yang adil dalam setiap transaksi. Perusahaan siap mengorbankan pendapatannya untuk terus meningkatkan produk dan layanannya. Keadilan dalam kegembiraan sangat penting artinya tidak menuai keuntungan besar dan keuntungan pelanggan sedikit dari perushaan.

\section{a. Esteem}

Konsumen merasa mendapatkan pelayanan yang sangat baik dari perusahaan. Perusahaan dapat membangkitkan kegembiraan dengan meningkatkan kesenangan pelanggan. Kesenangan 
pelanggan cenderung meningkat dengan menerima layanan yang sangat personal. Demikian pula, memberi satu prioritas dan secara aktif mencari pendapatnya juga membantu menaikkan kesenangan pelanggan.

\section{Security}

Konsumen ingin merasa aman dalam berbelanja dan kepentingannya dilindungi.Hal ini diperlukan untuk menjaga agar atmosfer benar-benar bersih dan rapi sehingga bisa mengantarkan sekaligus menjaga pikiran pelanggan yang damai.

\section{Trust}

Kepercayaan adalah konstruksi yang dipelajari dengan baik dalam pemasaran. Kepercayaan dalam kegembiraan mengacu pada manajemen krisis terbaik dimana perusahaan bertanggung jawab penuh atas kesalahannya dan mengakui terus terang. Penanganan saat terjadi permasalahan seperti krisis manajemen dimana perusahaan seharusnya dapat bertanggung jawab penuh terhadap kesalahannya dan mengakuinya secara terbuka.

\section{Variety}

Variasi diusulkan menjadi faktor yang relevan, dikatakan bahwa keragaman setara dengan kejutan bahwa keduanya menarik perhatian konsumen. Variasi merupakan cara memberikan kejutan untuk menarik perhatian pelanggan. Perusahaan juga mampu untuk memberikan produk dan jasa yang baru secara berkala.

\section{METODE}

Berdasarkan tujuan penelitian yang telah dikemukakan sebelumnya, penelitian ini menggunakan metode deskriptif dengan perhitungan kuantitatif. Menurut Hasan (2002, hlm. 22), metode deskriptif adalah suatu metode yang menitik beratkan kepada observasi dan suasana ilmiah, digunakan untuk melukiskan secara sistematis fakta atau karakteristik populasi tertentu atau bidang tertentu secara aktual dan cermat. Teknik analisis deskriptif digunakan ketika menyajikan data tentang responden, penyajian data tentang Servicescape sesuai dengan data pengunjung. Disajikan dengan cara deskriptif agar memudahkan dalam membaca dan menganalisis secara statistik. Menurut Sugiyono (2014, hlm. 8) metode kuantitatif metode penelitian yang berlandaskan pada filsafat positivisme, digunakan untuk meneliti pada populasi atau sample tertentu, pengumpulan data menggunakan instrumen penelitian, analisis data bersifat kuantitatif/statistik, dengan tujuan untuk menguji hipotesis yang telah di tetapkan. Penelitian yang dilakukan untuk mengetahui nilai variabel mandiri, baik satu variabel atau lebih.

Pada penelitian ini dengan metode deskriptif dan kuantitatif, dapat mengetahui seberapa besar Pengaruh Servicescape Terhadap Customer Delight Pada Tamu Resort. Dengan metode deskriptif dapat mengetahui kondisi sebuah resort secara aktual. Mengumpulkan data primer dan data sekunder. Dengan metode kuantitatif menghitung seberapa besar pengaruh servisescape terhadap customer delight menggunakan teknik regresi linear berganda. Sedangkan untuk sampel penelitian ini yaitu sebanyak 100 responden yang pernah berkunjung atau menginap di resort. Proses pengambilan sampel dilakukan dengan nonprobability sampling.

\section{HASIL DAN PEMBAHASAN}

\section{Profil Tamu yang Pernah Menginap di Resort}

Profil tamu merupakan data pengunjung yang pernah menginap di resort. Untuk mengetahui karakteristik tamu yang menginap di resort, maka disebarkan kuesioner 100 responden sebagai sampel penelitian.

a. Karakteristik Tamu Berdasarkan Jenis Kelamin

Hasil pengumpulan data dari 100 responden dari jenis kelamin dapat dilihat pada gambar 2 sebagai berikut : 


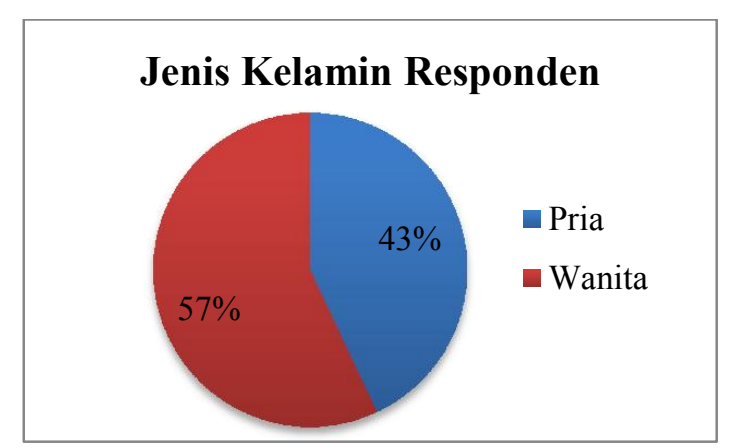

Gambar 2. Diagram Presentase Jenis Kelamin Responden

Sumber: Hasil pengolahan data (2017)

Berdasarkan gambar 2 dapat disimpulkan bahwa jumlah persentase tamu perempuan $(57 \%)$ lebih banyak dibandingkan dengan tamu pria. Dikarenakan tamu perempuan menginap atau berkunjung untuk bersenang-senang menikmati suasana resort dan melakukan aktivitas yang disediakan oleh resort. Sementara untuk tamu pria dengan jumlah presentase $(43 \%)$ jumlah ini tidak terlalu jauh dengan jumlah tamu perempuan, hal ini mengindikasikan bahwa resort dapat dinikmati oleh wanita, dan pria juga memiliki ketertarikan untuk menginap atau berkunjung di sebuah resort.

b. Karkateristik Tamu Berdasarkan Usia

Hasil pengumpulan data dari 100 responden dari segi usia dapat dilihat pada gambar 3 sebagai berikut :

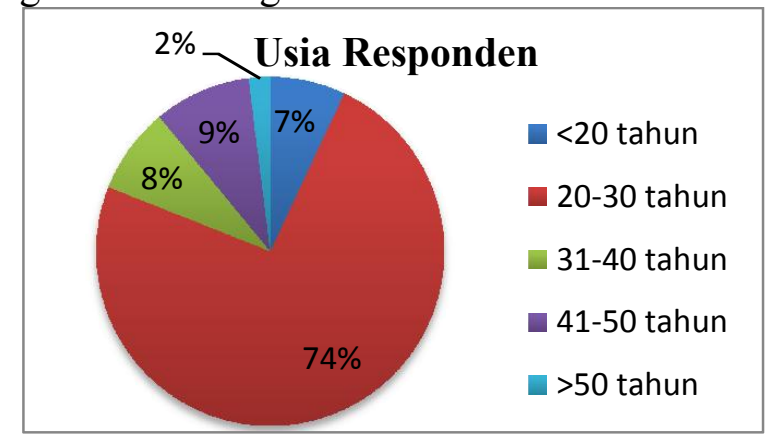

Gambar 3. Diagram Presentase Berdasarkan Usia Responden

Sumber: Hasil pengolahan data (2017)

Berdasarkan gambar 3 dapat disimpulkan bahwa tamu atau wisatawan yang pernah menginap atau berkunjung di resort didominasi oleh pengunjung dengan usia 2030 tahun (74\%), hal tersebut dikarenakan usia 20-30 tahun masih dalam masa produktif, dan memilki kesibukan pekerjaan yang biasanya melakukan perjalanan wisata bersama instansi pekerjaan atau keluarga. Tamu yang berusia 41-50 tahun (9\%), tamu pada usia ini rata-rata orang tua yang sedang berlibur atau melakukan kegiatan pertemuan bersama rekan kerja. Kemudian tamu dengan usia 31-40 tahun berjumlah (8\%), tamu usia 31-40 tahun biasanya selain untuk berlibur juga beberapa untuk melakukan perjalanan bsinis. Tamu pada usia $<20(7 \%)$ tahun masih sangat produktif memiliki keaktifan dan keingintahuan yang tinggi, senang bermain, berkumpul mencoba hal baru. Tamu pada usia $>50$ tahun merupakan tamu minoritas, dengan usia ini rata-rata menginap atau berkunjung di resort untuk menikmati suasana dan keindahan alam bersama keluarga.

c. Karakteristik Tamu Berdasarkan Tujuan Menginap

Hasil pengumpulan data dari 100 responden dari segi tujuan menginap dapat dilihat pada gambar 4 sebagai berikut :

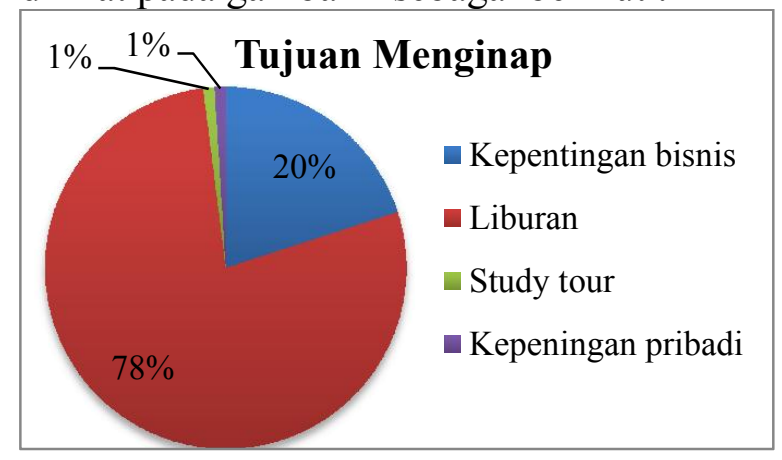

Gambar 4. Diagram Presentase

Berdasarkan Tujuan Menginap

Sumber: Hasil pengolahan data (2017)

Berdasarkan gambar 4 dapat disimpulkan bahwa tamu yang menginap di resort lebih banyak datang dengan tujuan liburan. Hal tersebut dikarenakan fungsi utama sebuah resort yaitu untuk wisata rekreasi dengan jumlah 78\%. Jumlah terbanyak kedua yaitu $20 \%$ dengan tujuan kepentingan bisnis. Kemudian responden mengisi lainnya sebanyak 2\% dengan tujuan adanya kerjasama dengan sebuah resort atau sekedar melakukan kegiatan studi. 
Dewi Mei Liyani, A.H.G. Kusumah dan Rosita: Pengaruh Servicescape Terhadap Customer Delight Pada Tamu Resort

(Survey Pada Tamu yang Pernah Menginap di Resort)

d. Karakteristik Tamu Berdasarkan Informasi

Hasil pengumpulan data dari 100 responden dari segi informasi dapat dilihat pada gambar 5 sebagai berikut :

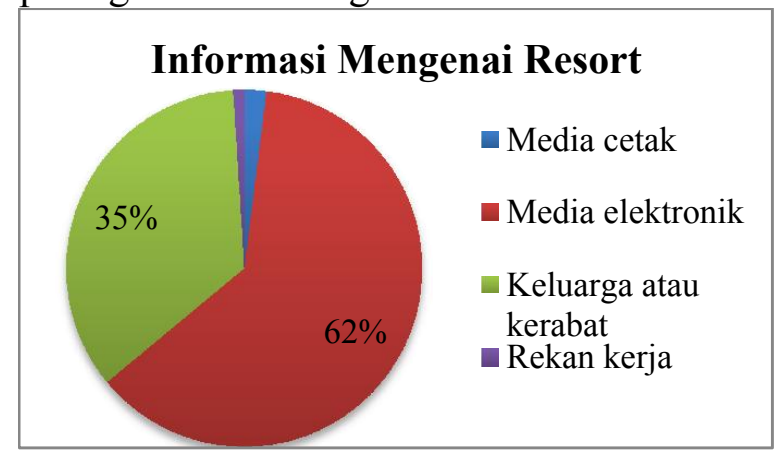

Gambar 5. Diagram Presentase

Berdasarkan Informasi

Sumber: Hasil pengolahan data (2017)

Berdasarkan gambar 5 dapat disimpulkan bahwa tamu yang menginap di resort mendapat informasi mengenai resort tersebut melalui media elektronik dengan jumlah $62 \%$. Hal tersebut dikarenakan promosi terbesar sebuah resort adalah melalui situs website. Selanjutnya 35\% melalui keluarga atau kerabat, 3\% melalui media cetak dan melalui lainnya.

e. Karakteristik Tamu Berdasarkan Lokasi Menginap

Hasil pengumpulan data dari 100 responden dari segi lokasi menginap dapat dilihat pada gambar 6 sebagai berikut :

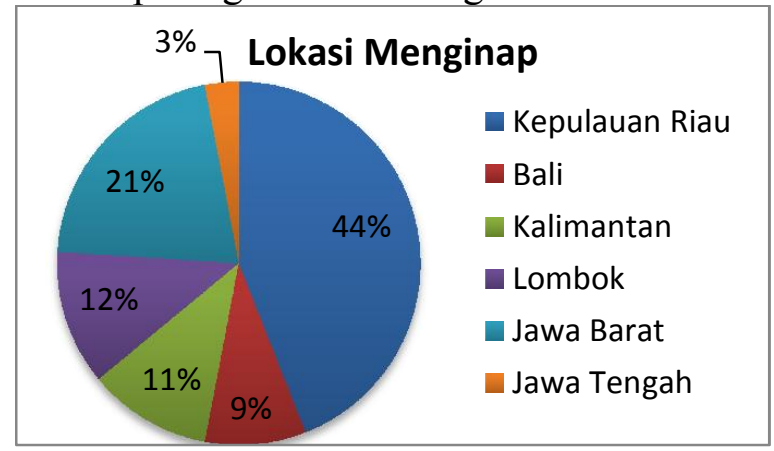

Gambar 6. Diagram Presentase Berdasarkan Lokasi Menginap

Sumber: Hasil pengolahan data (2017)

Berdasarkan gambar 6 dapat disimpulkan bahwa dari 100 responden, dengan jumlah terbesar yaitu $44 \%$ menginap di resort yang ada di Kepulauan Riau, dimana 34 orang menginap di Nirwana Gardens Resort Bintan, 4 orang menginap di Treasure bay Bintan, 4 Orang di Club Med Bintan, dan 2 orang di Banyan Tree Resort Bintan. Kemudian sebanyak $21 \%$ responden menginap di resort yang ada di Jawa Barat, 13 orang menginap di The Green Forest Resort, 7 orang menginap di Dusun Bambu, 1 orang menginap di Padma Resort \& Hotel Bandung, kemudian sebanyak $12 \%$ menginap di resort yang berada di Lombok, 9 orang menginap di Puri Air Beach Resort and Spa dan 1 orang menginap Katamaran Hotel \& Resort. Selanjutnya sebesar 11\% wisatawan menginap di resort yang ada di Kalimantan, 9 orang menginap di Derawan Dive Resort dan 2 orang menginap di Maratua Paradise Resort. Kemudian pulau Bali menjadi salah satu tujuan wisatawan dengan jumlah $9 \%, 8$ orang menginap di Nusa Dua Beach \& Spa dan 1 orang menginap di Club Med Bali. Terakhir dengan jumlah 3\% wisatawan menginap di resort yang berada di Jawa Tengah, dimana 2 orang menginap di Villa Borobudur Resort dan 1 orang menginap di Kura-Kura Resort Karimunjawa.

\section{Rekapitulasi Dimensi Servicescape Pada Tamu Resort}

Rekapitulasi mengenai tanggapan tamu terhadap servicescape di resort ditunjukan pada tabel 1 .

Tabel 1. Rekapitulasi Dimensi Servicescape di Resort

\begin{tabular}{ccccc}
\hline No & Sub Variabel & $\begin{array}{c}\text { Total } \\
\text { Skor }\end{array}$ & $\begin{array}{c}\text { Jumlah Item } \\
\text { Pernyataan }\end{array}$ & $\begin{array}{c}\text { Rata-rata } \\
\text { Skor }\end{array}$ \\
\hline 1 & Ambient Factors & 1255 & 3 & 418 \\
\hline 2 & Design Factors & 1590 & 4 & 398 \\
\hline 3 & Social Factors & 796 & 2 & 398 \\
\hline & Total & $\mathbf{3 . 6 4 1}$ & $\mathbf{9}$ & $\mathbf{1 . 2 1 4}$ \\
\hline
\end{tabular}

Sumber: Hasil pengolahan data (2017)

Tabel 1 menunjukan bahwa dimensi ambient factors memperoleh penilaian tertinggi menurut responden dengan skor rata-rata 418. Hal ini dikarenakan penilaian yang bersifat non visual seperti suasana, aroma, suhu cukup sulit untuk dibentuk standar bagi tamu karena kepekaan dan 
selera bisa bervariasi. Kemudian design factors dan social factors dengan skor ratarata yang sama yaitu 398. Berikut merupakan cara dalam menghitung servicescape di resort :

a. Nilai indeks maksimum $=$ skor tertinggi $\mathrm{x}$ jumlah pernyataan $\mathrm{x}$ jumlah responden

Nilai indeks maksimum $=5 \times 9 \times 100=$ 4.500

b. Nilai indeks minimum $=$ skor terendah $\mathrm{x}$ jumlah pernyataan $\mathrm{x}$ jumlah responden

Nilai indeks minimum $=1 \times 9 \times 100=$ 900

c. Jenjang variabel = nilai indeks maksimum - nilai indeks minimum Jenjang variabel $=4.500-900=3.600$

d. Jarak Interval $=$ jenjang variabel : banyak kelas interval

Jenjang interval $=3.600: 5=720$

e. Presentase skor $=($ total skor : nilai indeks maksimum) $\times 100 \%$

Presentase skor $=(3641: 4500) \times 100 \%=$ $80,9 \%$

Berdasarkan perhitungan, skor ideal yang diharapkan untuk tanggapan responden terhadap servicescape dari keseluruhan item pernyataan yaitu sebesar 4500. Hasil yang diperoleh dengan presentase $80,9 \%$ dari skor ideal yang diharapkan yaitu sebesar 3641 . Hasil tersebut menunjukan bahwa servicescape di resort mendapat respon yang cukup baik dari tamu sebagai responden. Apabila presentase tersebut digambarkan dalam garis kontinum, maka dapat ditunjukan dalam gambar 7 berikut.

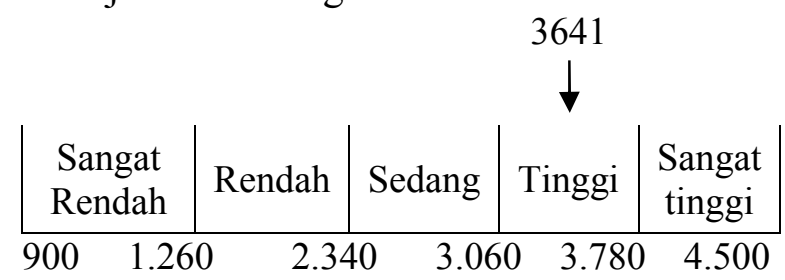

\section{Gambar 7. Garis Kontinum Servicescape di Resort \\ Sumber: Hasil pengolahan data (2017)}

Gambar 7 dengan garis kontinumnya menunjukan bahwa penilaian responden akan servicescape di resort terdapat dikategori tinggi dengan skor 3641 atau sebesar $80,9 \%$. Hal ini menunjukan bahwa daya tarik visual maupun non visual sudah dinilai baik oleh tamu.

\section{Rekapitulasi Dimensi Customer Delight Pada Tamu Resort}

Rekapitulasi mengenai tanggapan tamu terhadap customer delight di resort ditunjukan pada tabel 2 .

Tabel 2. Rekapitulasi Dimensi Customer Delight di Resort

\begin{tabular}{ccccc}
\hline No & $\begin{array}{c}\text { Sub } \\
\text { Variabel }\end{array}$ & $\begin{array}{c}\text { Total } \\
\text { Skor }\end{array}$ & $\begin{array}{c}\text { Jumlah Item } \\
\text { Pernyataan }\end{array}$ & $\begin{array}{c}\text { Rata-rata } \\
\text { Skor }\end{array}$ \\
\hline 1 & Justice & 1215 & 3 & 405 \\
\hline 2 & Esteem & 1150 & 3 & 383 \\
\hline 3 & Security & 823 & 2 & 412 \\
\hline 4 & Trust & 776 & 2 & 388 \\
\hline 5 & variety & 788 & 2 & 394 \\
\hline \multicolumn{2}{c}{ Total } & $\mathbf{4 . 7 5 2}$ & $\mathbf{1 2}$ & $\mathbf{1 . 9 8 2}$ \\
\hline
\end{tabular}

Sumber: Hasil pengolahan data (2017)

Tabel 2 menunjukan bahwa dimensi security memperoleh penilaian tertinggi menurut responden dengan skor rata-rata 412. Hal ini dikarenakan konsumen ingin merasa aman dalam kegiatannya selama berada di resort dan kepentingannya dilindungi. Hal ini diperlukan untuk menjaga agar atmosfer benar-benar bersih dan rapi sehingga bisa mengantarkan sekaligus menjaga pikiran pelanggan yang damai. Kemudian penilaian terendah yaitu pada dimensi esteem dengan rata-rata skor sebesar 384. Tamu merasa diistimewakan dengan pelayanan yang diberikan dirasa kurang oleh tamu yang menginap. Berikut merupakan cara dalam menghitung customer delight di resort :

a. Nilai indeks maksimum $=$ skor tertinggi $\mathrm{x}$ jumlah pernyataan $\mathrm{x}$ jumlah responden

Nilai indeks maksimum $=5 \times 21 \times 100=$ 10.500

b. Nilai indeks minimum $=$ skor terendah $\mathrm{x}$ jumlah pernyataan $\mathrm{x}$ jumlah responden

Nilai indeks minimum $=1 \times 21 \times 100=$ 2.100

c. Jenjang variabel = nilai indeks maksimum - nilai indeks minimum Jenjang variabel $=10.500-2.100=8.400$ 
Dewi Mei Liyani, A.H.G. Kusumah dan Rosita: Pengaruh Servicescape Terhadap Customer Delight Pada Tamu Resort

(Survey Pada Tamu yang Pernah Menginap di Resort)

d. Jarak Interval $=$ jenjang variabel : banyak kelas interval

Jenjang interval $=8.400: 5=720$

e. Presentase skor $=($ total skor : nilai indeks maksimum) x $100 \%$

Presentase skor $=(4.752: 10.500) \mathrm{x}$

$$
100 \%=45,3 \%
$$

Berdasarkan perhitungan, skor ideal yang diharapkan untuk tanggapan responden terhadap customer delight dari keseluruhan item pernyataan yaitu sebesar 10.500 . Hasil yang diperoleh dengan presentase 45,3\% dari skor ideal yang diharapkan yaitu sebesar 4.752. Hasil tersebut menunjukan bahwa customer delight di resort mendapat respon yang cukup baik dari tamu sebagai responden. Apabila presentase tersebut digambarkan dalam garis kontinum, maka dapat ditunjukan dalam gambar 8 berikut.

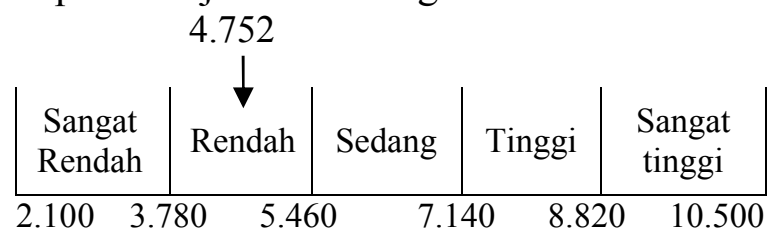

\section{Gambar 8. Garis Kontinum Customer Delight di Resort \\ Sumber: Hasil pengolahan data (2017)}

Gambar 9 dengan garis kontinumnya menunjukan bahwa penilaian responden akan customer delight di resort terdapat dikategori rendah dengan skor 4752 atau sebesar $45,3 \%$. Hal ini menunjukan bahwa keadilan, keistimewaan, keamanan, kepercayaan, hingga pelayanan yang tidak terduga sebelumnya (variasi) dinilai tidak cukup baik oleh tamu.

\section{Pengaruh Servicescape Terhadap}

Customer Delight Pada Tamu Resort

Pengujian hipotesis dilakukan untuk menguji besarnya pengaruh program servicescape $(\mathrm{X})$ yang terdiri dari ambient factors $\left(\mathrm{X}_{1}\right)$, design factors $\left(\mathrm{X}_{2}\right)$, social factors $\left(\mathrm{X}_{3}\right)$ terhadap customer delight $(\mathrm{Y})$. Hasil korelasi antara servicescape dengan customer delight disajikan dalam tabel 3 berikut.
Tabel 3. Matrik Korelasi Antara Sub Variabel Servicescape Dengan Customer Delight Pada Tamu Resort

\begin{tabular}{lcccc}
\hline $\begin{array}{c}\text { Variabel/ } \\
\text { Sub Variabel }\end{array}$ & $\begin{array}{c}\text { Ambient } \\
\text { Facotrs } \\
\text { (X1) }\end{array}$ & $\begin{array}{c}\text { Factors } \\
\text { (X2) }\end{array}$ & $\begin{array}{c}\text { Social } \\
\text { Factors } \\
(\mathrm{X} 3)\end{array}$ & $\begin{array}{c}\text { Customer } \\
\text { Delight } \\
(\mathrm{Y})\end{array}$ \\
\hline Ambient Factors $(\mathrm{X} 1)$ & 1 & 0,708 & 0,591 & 0,678 \\
\hline Design Factors $(\mathrm{X} 2)$ & 0,708 & 1 & 0,675 & 0,750 \\
\hline Social Factors $(\mathrm{X} 3)$ & 0,591 & 0,675 & 1 & 0,818 \\
\hline Customer Delight $(\mathrm{Y})$ & 0,678 & 0,750 & 0,818 & 1 \\
\hline
\end{tabular}

Sumber: Hasil pengolahan data (2017)

Berdasarkan hasil matrik korelasi antara sub variabel servicescape yaitu ambient factors $\left(\mathrm{X}_{1}\right)$, design factors $\left(\mathrm{X}_{2}\right)$, social factors $\left(\mathrm{X}_{3}\right)$, terhadap customer delight $(\mathrm{Y})$ diperoleh hasil korelasi secara berurutan yaitu ambient factors $(0,678)$, design factors $(0,750)$, social factors $(0,818)$ hal tersebut menunjukan terdapat hubungan antara sub variabel servicescape dengan customer delight. Nilai positif dari sub variabel $\mathrm{X}_{1}$, $\mathrm{X}_{2}, \mathrm{X}_{3}$ terhadap $\mathrm{Y}$ artinya semakin besar nilai sub variabel $\mathrm{X}_{1}, \mathrm{X}_{2}, \mathrm{X}_{3}$ maka semakin besar nilai Y.

Berdasarkan hasil kolerasi, selanjutnya akan dilakukan pengujian hipotesis keseluruhan untuk mengetahui hasil hipotesis. Tabel anova merupakan uji simultan untuk melihat pengaruh metode interpretasi terhadap customer delight. Berikut hipotesis yang akan diuji :

$\mathrm{H}_{0}$ ditolak jika $\mathrm{F}_{\text {hitung }}>\mathrm{F}_{\text {tabel, }}$, artinya terdapat pengaruh servicescape terhadap customer delight.

$\mathrm{H}_{0}$ diterima jika $\mathrm{F}_{\text {hitung }}<\mathrm{F}_{\text {tabel }}$, artinya tidak terdapat pengaruh servicescape terhadap customer delight.

Statistik uji :

$F h=\frac{R^{2} / k}{\left(1-R^{2}\right) /(n-k-1)}$

(Sugiyono, 2013:235)

Ftabel $=\mathrm{F}_{\mathrm{a}:(\mathrm{dfl}, \mathrm{d} \mathrm{d} 2)}: \mathrm{df}=\mathrm{k}, \mathrm{df} 2=\mathrm{n}-\mathrm{k}-1$

$\alpha \quad=5 \%$

Mengunakan tabel distribusi $F$ dengan probabilitas 0,05 didapat nilai $F_{\text {tabel }}$ sebesar 2,70. Hasil output tabel anova dengan menggunakan SPSS 24 sebagai berikut : 
Tabel 4. Anova

\begin{tabular}{|c|c|c|c|c|c|c|}
\hline & \multicolumn{6}{|c|}{ ANOVA $^{a}$} \\
\hline & Model & $\begin{array}{l}\text { Sum of } \\
\text { Squares }\end{array}$ & df & $\begin{array}{c}\text { Mean } \\
\text { Square }\end{array}$ & $\mathrm{F}$ & Sig. \\
\hline 1 & Regression & 35,909 & 3 & 11,970 & 98,576 &, $000^{\mathrm{b}}$ \\
\hline & Residual & 11,657 & 96 & 121 & & \\
\hline & Total & 47,565 & 99 & & & \\
\hline
\end{tabular}

a. Dependent Variable: customer delight

b. Predictors: (Constant), social factors, ambient factors, design factors

Sumber: Hasil pengolahan data (2017)

Dari tabel diatas didapatkan hasil $\mathrm{F}_{\text {hitung }}$ sebesar 98,576 dengan tingkat signifikan 0,000 . Untuk menguji hipotesis variabel servicescape $(\mathrm{X})$ dengan variabel customer delight (Y) digunakan tabel anova. Tabel anova dilakukan dengan membandingkan $F_{\text {hitung dengan }} F_{\text {tabel}}$, pada taraf nyata $\alpha=5 \%$. Berdasarkan tabel 4.12 dapat disimpulkan bahwa diketahui nilai signifikansi untuk pengaruh $\mathrm{X}_{1}, \mathrm{X}_{2}$, dan $\mathrm{X}_{3}$ secara simultan terhadap $\mathrm{Y}$ adalah sebesar $0,000<0,05$ dan nilai $F_{\text {hitung }} 98,576>F_{\text {tabel }} 2,70$. Sehingga dapat disimpulkan bahwa variabel servicescape signifikan berpengaruh terhadap customer delight pada tamu resort.

\section{Uji T Hitung}

Uji $\mathrm{T}$ hitung adalah uji parsial yang digunakan untuk melihat apakah terdapat pengaruh antara servicescape terhadap customer delight. Oleh karena hasil pengujian keseluruhan signifikan, maka selanjutnya dilakukan pengujian signifikansi masing-masing koefisien. Kriteria keputusan hipotesis diterima apabila $\mathrm{T}_{\text {hitung }}>\mathrm{T}_{\text {tabel }}$. menggunakan tabel distribusi $\mathrm{T}$ dengan probabilitas 0,05 didapat nilai Ttabel sebesar 1,988. Hasil output tabel uji $\mathrm{T}_{\text {hitung }}$ dengan menggunakan SPSS 24 sebagai berikut :
Tabel 5. Hasil Penguji Koefisien

\begin{tabular}{|c|c|c|c|c|c|c|}
\hline & & & Coeff & cients $^{a}$ & & \\
\hline & & $\begin{array}{r}\text { Unstand } \\
\text { Coeffi }\end{array}$ & $\begin{array}{l}\text { ardized } \\
\text { cients }\end{array}$ & $\begin{array}{c}\text { Standardized } \\
\text { Coefficients }\end{array}$ & & \\
\hline & Model & $\mathrm{B}$ & $\begin{array}{l}\text { Std. } \\
\text { Error }\end{array}$ & Beta & $t$ & Sig. \\
\hline 1 & (Constant) & ,616 & ,205 & & 2,997 &, 003 \\
\hline & $\begin{array}{l}\text { ambient } \\
\text { factors }\end{array}$ & 158 & 066 & 174 & 2,369 & ,020 \\
\hline & $\begin{array}{l}\text { design } \\
\text { factors }\end{array}$ & 240 & ,073 & 264 & 3,297 & ,001 \\
\hline & $\begin{array}{l}\text { social } \\
\text { factors }\end{array}$ & ,443 & 058 &, 537 & 7,657 &, 000 \\
\hline
\end{tabular}

a. Dependent Variable: customer delight

Sumber: Hasil pengolahan data (2017)

Hasil pengujian Hipotesis $\mathrm{H}_{1}, \mathrm{H}_{2}, \mathrm{H}_{3}$, dandengan uji $\mathrm{T}$ hitung sebagai berikut :

a. Diketahui nilai sig untuk pengaruh $\mathrm{X}_{1}$ terhadap $\mathrm{Y}$ adalah sebesar $0,020<0,05$ dan nilai $\mathrm{T}_{\text {hitung }} 2,369>\mathrm{T}_{\text {tabel }} 1,988$ sehingga dapat disimpulkan bahwa $\mathrm{H}_{1}$ ditolak yang berarti terdapat pengaruh $\mathrm{X}_{1}$ terhadap $\mathrm{Y}$.

b. Diketahui nilai sig untuk pengaruh $\mathrm{X} 2$ terhadap $\mathrm{Y}$ adalah sebesar $0,001<0,05$ dan nilai $\mathrm{T}_{\text {hitung }} 3,297>\mathrm{T}_{\text {tabel }} 1,988$ sehingga dapat disimpulkan bahwa $\mathrm{H}_{2}$ ditolak yang berarti terdapat pengaruh $\mathrm{X}_{2}$ terhadap Y.

c. Diketahui nilai sig untuk pengaruh X3 terhadap $\mathrm{Y}$ adalah sebesar $0,000<0,05$ dan nilai $\mathrm{T}_{\text {hitung }} 7,657>\mathrm{T}_{\text {tabel }} 1,988$ sehingga dapat disimpulkan bahwa $\mathrm{H}_{3}$ ditolak yang berarti terdapat pengaruh $\mathrm{X}_{3}$ terhadap Y.

Tabel 5 menunjukan bahwa pengujian individual koefisien korelasi $\mathrm{X}$ terhadap $\mathrm{Y}$ memenuhi kriteria karena nilai signifikansi lebih kecil dibandingkan dengan 0,05 dan $\mathrm{T}_{\text {hitung }}>\mathrm{T}_{\text {tabel }}$ sehingga dapat disimpulkan sub variabel servicescape yaitu ambient factors $\left(\mathrm{X}_{1}\right)$, design factors $\left(\mathrm{X}_{2}\right)$, social factors $\left(\mathrm{X}_{3}\right)$ memiliki pengaruh yang signifikan terhadap customer delight (Y). Secara lengkap pengaruh masing-masing program servicescape terhadap customer 
Dewi Mei Liyani, A.H.G. Kusumah dan Rosita: Pengaruh Servicescape Terhadap Customer Delight Pada Tamu Resort

(Survey Pada Tamu yang Pernah Menginap di Resort)

delight disajikan dalam gambar 9 sebagai berikut :

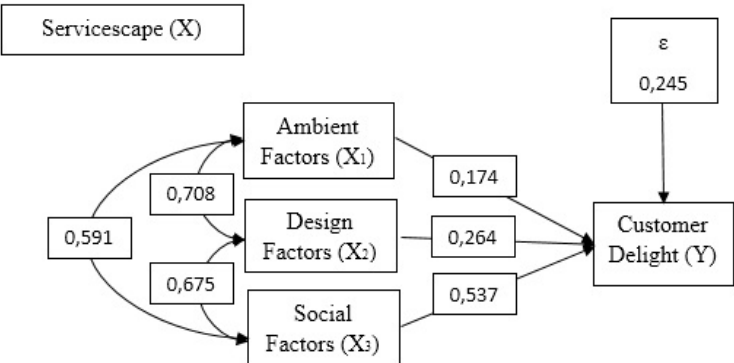

Gambar 9. Diagram Pengujian Hipotesis $\mathbf{X}$ Terhadap $\mathbf{Y}$

Sumber: Hasil pengolahan data (2017)

Berdasarkan diagram pengujian hipotesis pada gambar 9 maka dilakukan perhitungan untuk mengetahui pengaruh langsung dan tidak langsung antara dimensi-dimensi yang disajikan dalam tabel 6 berikut :

Tabel 6. Hasil Pengujian Koefisien Pengaruh Langsung dan Tidak Langsung Servicescape Terhadap Customer Delight Pada Tamu Resort

\begin{tabular}{|c|c|c|c|c|c|c|c|}
\hline \multirow[t]{2}{*}{$\mathrm{x}$} & \multirow{2}{*}{$\begin{array}{c}\text { Koefisien } \\
\text { beta }\end{array}$} & \multirow{2}{*}{$\begin{array}{l}\text { Pengaruh } \\
\text { Langsung }\end{array}$} & \multicolumn{3}{|c|}{ P. Tidak Langsung } & \multirow{2}{*}{$\begin{array}{l}\text { Total P. } \\
\text { Tidak } \\
\text { Langsung }\end{array}$} & \multirow{2}{*}{$\begin{array}{c}\text { Total } \\
\text { Pengaruh }\end{array}$} \\
\hline & & & $\mathrm{X} 1$ & $\mathrm{X} 2$ & $\mathrm{X} 3$ & & \\
\hline $\mathrm{X} 1$ & 171 & 0,03 & & 0,033 & 0,055 & 0,088 & 0,118 \\
\hline 2 & & & 0,033 & & 0,084 & & \\
\hline \multirow[t]{2}{*}{$\mathrm{X} 3$} & & & 0,055 & 0,084 & & 0,139 & 0,429 \\
\hline & \multicolumn{5}{|c|}{ Total Pengaruh } & & 0,734 \\
\hline
\end{tabular}

Sumber: Hasil pengolahan data (2017)

Berdasarkan hasil perhitungan diatas dapat diketahui bahwa pengaruh total program servicescape terhadap customer delight adalah sebesar 0,734 atau $73,4 \%$ sedangkan koefisien variabel lain diluar variabel servicescape ditentukan melalui :

$\operatorname{Px} 2 \varepsilon=\sqrt{1-R^{2} \times 2(x 1 . x 2 . x 3)}$

$=\sqrt{1-0,734}$

$=0,5157$

Hal tersebut berarti bahwa $\left(\mathrm{X}_{1}\right),\left(\mathrm{X}_{2}\right)$, dan $\left(\mathrm{X}_{3}\right)$ bersama-sama mempengaruhi customer delight sebesar $73,4 \%$ dan sisanya sebesar $(0,5157)^{2}=0,2659 \times 100 \%=26,59 \%$ dipengaruhi oleh faktor lain yang tidak termasuk ke dalam penelitian ini. Kondisi ini mengindikasikan servicescape dapat mempengaruhi customer delight dan faktor lain di luar dari servicescape tidak memiliki pengaruh lebih besar.

\section{KESIMPULAN}

1. Gambaran mengenai servicescape di 15 resort mendapat penilaian baik dari tamu yang menginap. Penilaian tertinggi diperoleh melalui ambient factors sedangkan untuk design factors dan social factors mendapatkan penilaian yang hampir sama.

a. Ambient factors memperoleh penilian tertinggi menurut tamu dikarenakan pengunjung merasa senang dengan fasilitas fisik yang diberikan oleh pengelola di resort, sesuai dengan kondisi fasilitas yang sangat beragam ini membuat wisatawan merasa senang terhadap aktivitas yang dilakukan disana.

b. Design factors mendapat penilaian sedikit dibawah ambient factors walaupun masih dikategori tinggi. Dikarenakan design factors yang diterapkan dengan mendatangkan barangbarang berkualitas terbaik dan design menarik agar dapat menciptakan kesan mewah kepada tamu mudah didapat dengan melihat design factors yang ada.

c. Sedangkan social factors mampu menciptakan kekeluargaan antara karyawan dengan pelanggan, dengan berbagai macam aktivitas disana menimbulkan interaksi antara tamu dengan tamu juga tamu dengan karyawan sehingga aktivitas yang disediakan oleh resort mampu menciptakan kekeluargaan dengan karyawan dan sesama tamu.

2. Gambaran mengenai customer delight di resort mendapat penilaian rendah dari tamu yang menginap. Penilaian tertinggi diperoleh melalui justice sedangkan penilaian terendah diperoleh esteem dengan penjelasan sebagai berikut.

a. Justice mendapatkan nilai tertinggi dikarenakan mampu menjaga harapan tamu saat mendapat informasi agar sesuai dengan kenyataan pada saat tamu menginap sehingga tamu merasa pihak resort telah berlaku jujur. 
b. Esteem berada pada tingkat paling rendah dikarenakan "mendapatkan pelayanan yang sangat baik dan dapat membangkitkan kegembiraan dengan meningkatkan kesenangan pelanggan" dirasa kurang oleh tamu yang menginap dibandingkan dengan kelima sub variabel lainnya.

3. Hasil penelitian menunjukan bahwa terdapat pengaruh antara servicescape terhadap customer delight pada tamu resort secara simultan maupun parsial. Pengaruh servicescape terhadap customer delight secara simultan sudah terbilang besar, secara parsial dimensi servicescape yang memiliki pengaruh terbesar adalah ambient factors diikuti oleh social factors dan design factors yang memiliki pengaruh hampir sama. Hal ini menandakan bahwa variabel servicescape (X) mempunyai pengaruh positif terhahadap customer delight (Y) yang dihasilkan memuaskan dengan diperoleh presentase sebesar $73,4 \%$ dan sisanya 26 , $59 \%$ dipengaruhi oleh variabel lain yang tidak peneliti teliti.

\section{DAFTAR PUSTAKA}

Hariri, Afwan. (2009). Pengaruh Customer Delight terhadap Customer Loyalty pada Siswa LBPP-LIa Malang. Jurnal Ekonomi dan Bisnis, 14(1), 70-79.

Hasan, Iqbal. (2002). Pokok - Pokok Materi Metodologi Penelitian dan
Aplikasinya. Jakarta : Ghalia Indonesia.

Hightower, R., Shariat, M. (2009). Servicescape's Hierarchical FactorStructure Model. Global Review of Business and Economic Research, Vol. 5 No.2, pp. 375-398

Kusumah, A.H.G. (2017). A Conceptual Framework of The Indonesian Resort Experience. The Hong Kong Polytechnic University.

Kwong, K. K., \& Yau, O. H. (2002). The Conceptualization of CustomerDelight: A Research Framework. Asia Pacific Management Review 7(2), 255-266.

Sugiyono. (2014). Metode Penelitian Pendidikan Pendekatan Kuantitatif, Kualitatif Dan R\&D. Bandung: Alfabeta.

Zeithaml, Valarie, Marry Jo Bitner, Dwayne D. Gremler. (2006). Service

Marketing. McGraw-Hill International Edition. 